University of Nebraska - Lincoln

DigitalCommons@University of Nebraska - Lincoln

April 2002

\title{
Factors Influencing Self-Rated Preparedness for Graduate School: A Survey of Graduate Students
}

\author{
Matthew T. Huss \\ Creighton University, mhuss@creighton.edu \\ Brandy A. Randall \\ University of Nebraska-Lincoln \\ Marc Patry \\ University of Nebraska-Lincoln \\ Stephen F. Davis \\ Emporia State University \\ David J. Hansen \\ Univertsity of Nebraska-Lincoln, dhansen1@unl.edu
}

Follow this and additional works at: https://digitalcommons.unl.edu/psychfacpub

Part of the Psychiatry and Psychology Commons

Huss, Matthew T.; Randall, Brandy A.; Patry, Marc; Davis, Stephen F.; and Hansen, David J., "Factors Influencing Self-Rated Preparedness for Graduate School: A Survey of Graduate Students" (2002). Faculty Publications, Department of Psychology. 102.

https://digitalcommons.unl.edu/psychfacpub/102

This Article is brought to you for free and open access by the Psychology, Department of at DigitalCommons@University of Nebraska - Lincoln. It has been accepted for inclusion in Faculty Publications, Department of Psychology by an authorized administrator of DigitalCommons@University of Nebraska - Lincoln. 


\title{
Factors Influencing Self-Rated Preparedness for Graduate School: A Survey of Graduate Students
}

\author{
Matthew T. Huss \\ Creighton University \\ Brandy A. Randall \& Marc Patry \\ University of Nebraska-Lincoln \\ Stephen F. Davis \\ Emporia State University \\ David J. Hansen \\ University of Nebraska-Lincoln
}

\begin{abstract}
Numerous studies have found a host of factors that are likely to result in more successful applications to graduate schools. This study was a retrospective examination of the variables that distinguish graduate students who believed they were better prepared for graduate school. We examined several of these factors, including variables associated with undergraduate education and the individual for their relation to self-rated preparedness for graduate school. Our findings highlighted quality faculty interactions and participation in research as important factors in graduate students' post hoc ratings of their preparedness for graduate school. We also found that different types of institutions differed in the degree to which these opportunities were available to or accessed by students.
\end{abstract}

A common concern for advisors of undergraduate psychology majors is how to best prepare students for graduate school. Some institutions have specific courses to assist students in preparing for and gaining admission to graduate school (Buskist, 1999). Researchers examining the question empirically have found a number of factors that contribute to graduate school admission. Courses in statistics and research methods, research experience, strong verbal and quantitative Graduate Record Exam (GRE) scores, high grade point averages (GPAs), good letters of recommendation, and strong personal statements are all considered essential for a competitive graduate school application (Couch \& Benedict, 1983; Landrum, Jeglum, \& Cashin, 1994; Purdy, Reinehr, \& Swartz, 1989; Smith, 1985). In addition, Purdy et al. considered previous applied work experience as important for admission to clinical and counseling programs.

There may be various educational experiences that influence the acquisition of these graduate school related accomplishments (e.g., publications or high GPA) and skills (e.g., clinical abilities gained from applied experiences). Although we have a solid understanding of the accomplishments and skills associ- ated with successful applications to graduate school, we wanted to obtain preliminary information regarding students' perceived preparation for graduate school. Do particular graduate students believe they were better prepared because of their undergraduate experiences or because of their personal characteristics? For example, some researchers have suggested that particular types of schools (i.e., private liberal arts) may be better at fostering the completion of out-of-class independent research projects (e.g., Kierniesky, 1984). These schools may be more advantageous to students seeking graduate school admission and prepare them better for graduate school success. Others have suggested that a more general concept such as mentoring may be an important variable in the preparation and success of students (Atkinson, Casas, \& Neville, 1994; Gilbert \& Rossman, 1992; Jacobi, 1991).

With regard to success once in graduate school, past studies (Habler, Vodanovich, \& Lowe, 1990; Hirschberg \& Itkin, 1978) have been limited in the criteria used for defining success or preparation for graduate school (e.g., early graduate school GPA) and may not fully account for the multifaceted accomplishments or the challenges graduate students face (e.g., research productivity, teaching skills, clinical ability). This study assessed graduate school preparedness in a more subjective but also a more inclusive manner: self-rated preparedness for graduate school. We examined students' exposure to experiences that were important for graduate preparation by asking students about their educational background after they had been admitted to and experienced the realities of graduate school. We hoped their ratings of their preparation for graduate school would provide converging evidence to support previous efforts that used more objective but restrictive dependent variables (e.g., graduate school GPA) when examining successful admission or success once in graduate school.

Students' self-rated preparedness can be viewed from the perspective of Bandura's (1977) theory regarding self-efficacy

Published in Teaching of Psychology 29:4 (2002), pp. 275-281. Teaching of Psychology is the official journal of the Society for the Teaching of Psychology. Copyright 2002 Lawrence Erlbaum Associates. Used by permission. Contact LEA http://www.erlbaum.com for permission to use or reprint. 
expectations, or beliefs about one's ability to succeed at a given task or behavior. A host of research has shown that both general academic self-efficacy and domain-specific academic efficacy predict academic persistence and performance above and beyond objective ability (see, e.g., Lent, Brown, \& Gore, 1997; Lent, Brown, \& Larkin, 1986). For example, research self-efficacy predicts graduate students' career goals as well as their research productivity (Kahn \& Scott, 1997). Indeed, because of the importance of self-efficacy, improving students' feelings of self-efficacy in such areas as test taking, research, and counseling has received considerable attention (Anderson, 1998; Griffin \& Griffin, 1997; Szymanski, Swett, Watson, Lin, \& Chan, 1998) Thus, assessing students' self-rated preparedness can provide an index of feelings of self-efficacy with regard to graduate school (domain-specific self-efficacy). Feelings of self-efficacy, in turn, are likely to influence graduate school performance.

Student preparedness for graduate school is likely dependent on a number of factors including individual characteristics (e.g., demographic characteristics, undergraduate GPA, GRE scores) and experiences at a particular undergraduate institution (e.g., research experience, courses offered, general mentoring experiences). In addition, we hypothesized that the experiences students had in their undergraduate years would differentially impact their perceived level of preparedness for graduate school along with a number of individual or personal characteristics. This study employed a path analytic model to identify the variables most related to students' self-rated preparedness for graduate school, after their admission and exposure to graduate school life.

\section{Method}

\section{Participants}

Participants consisted of 644 graduate students randomly selected from psychology programs across the United States. The sample of 218 men and 426 women had a mean age of 28.4 years $(S D=6.22)$. Participants were $86 \%$ White, $4.7 \%$ Hispanic, 3.7\% Asian American, 2.2\% African American, 0.5\% Native American, and $2.9 \%$ other racial or ethnic groups. The majority of participants $(83.2 \%)$ obtained their undergraduate degrees in psychology. At the majority of institutions, statistics $(93.2 \%)$ and experimental psychology $(93.3 \%)$ were required courses for psychology majors. Over half $(51.7 \%)$ the respondents graduated from public undergraduate universities, whereas $46.4 \%$ graduated from private institutions. A minority of participants were initiated as members of Psi Chi (43.9\%) as undergraduates or served as Psi Chi officers (10.6\%). Fifty-six percent of the sample was in clinical or counseling graduate programs, with the remaining 44\% coming from experimental areas of psychology (e.g., developmental, social, cognitive, biopsychology). Almost $90 \%(89.3 \%)$ were in doctorate programs, with $10.2 \%$ from terminal master's programs. Participants had been in graduate school about 3 years $(M=2.9)$ and graduated from their undergraduate institution approximately 2 years $(M=2.1)$ prior to admission into graduate school.

\section{Materials}

We used a detailed survey with selected questions to address the criteria important in admissions to graduate programs in psychology as identified by prior researchers. For example, we asked participants about their undergraduate GPAs, GRE scores, and whether they took statistics or experimental psychology courses as undergraduates. We formulated additional questions regarding their experiences at undergraduate institutions that might relate to perceived graduate school preparation. These questions focused on aspects such as their characterization of faculty interactions, number of scholarly presentations and publications, availability of opportunities for research and involvement in applied settings, confidence in the quality of their letters of recommendation, and Psi Chi membership. Participants also responded to questions concerning characteristics of their undergraduate program (public or private university, size, presence of a graduate program in psychology) and demographic questions (sex, age, race, household income). Therefore, the survey asked for objective assessments of past experiences, individual characteristics, and self-report ratings on the questions previously described.

\section{Procedure}

We randomly selected 25 schools from the American Psychological Association's (APA; 1996) Graduate Study in Psychology, including programs that offered either doctoral or terminal master's degrees. Institutions ranged from selective graduate programs to programs with more liberal admissions policies. Following school selection, we obtained estimates of the number of psychology graduate students enrolled in each program from the Graduate Study in Psychology. We sent surveys and explanatory letters to each department chair based on these estimates. We asked department chairs to distribute the surveys (with an explanatory letter from the investigators stapled to the front of each survey). Graduate students mailed the surveys in stamped self-addressed envelopes.

Of the original 25 schools selected, respondents from 20 returned surveys. The department chair at 1 school declined to participate, and 4 others did not respond to the initial request or a follow-up letter. From a total of 1,790 distributed, 664 students returned surveys (response rate $=36 \%$ ). This response rate is likely to be conservative. Our experience has suggested that most programs had fewer graduate students who were actively enrolled than indicated by the APA publication. Therefore, many of the original 1,790 surveys mailed were likely not distributed to active students because graduate students were not present on campus to obtain them.

\section{Results}

We conceptualized and conducted the data analysis in terms of a path analysis exploring indirect and direct relations among predictors and self-rated preparedness. Researchers use path analysis when it is theoretically accurate to causally order factors (e.g., institutional type precedes type of faculty interaction, 
which precedes conference presentations, which precedes selfrated preparedness). For example, path analysis enabled us to find both the direct effect of institutional type on self-rated preparedness and the indirect effect through the variables of faculty interaction and conference presentations. As a result, the path analysis creates a more complicated but also a more inclusive picture of the interrelations among variables. We measured the dependent variable in our path analysis, self-rated preparedness for graduate school, by asking participants, "How good was your preparation for graduate school?" Participants responded on a scale ranging from 1 (poor) to 5 (excellent; $M=3.91, S D$ $=0.98$ ).

We also included a host of predictor variables in a three-level path analysis. Of the 35 raw predictor variables included in the model, $4.9 \%$ of the original data points were missing. We either replaced missing values with the mean score on that variable, a "neutral" score for Likert-type items that included a neutral option, or as zero on dichotomous variables in which we used effect coding of -1 and +1 for completed responses. For example, we replaced missing scores on the faculty interaction variable with a 3 , the neutral option on the 5-point scale, and we replaced missing scores on the dichotomous question regarding whether a participants' undergraduate program had a graduate program $(-1=y e s, 1=n o)$ with a zero.

We used factor analysis to help identify variables that grouped together mathematically. To simplify the model, we aggregated some conceptually and mathematically consistent groups of variables into unit-weighted factors. We offer alpha levels for each of these groups along with their specific composition.

The GRE factor $(\alpha=.72$; range $=1,780$ to 3,$180 ; M=2,543$; $S D=221$ ) consisted of the sums of participant scores on the four GRE sections: analytical, quantitative, verbal, and psychology. We constructed undergraduate program $(\alpha=.78$; range $=-1$ to $7 ; M=2.1, S D=2.7$ ) by summing undergraduate program type $(-1=$ public, 1 = private $)$, whether the undergraduate program had a graduate program $(-1=y e s, 1=n o)$, and student body size $(1=20,000$ and above; $2=10,001$ to 20,$000 ; 3=5,001$ to 10,000; 4=1,001 to 5,000; and $5=$ less than 1,000).

Research activity $(\alpha=.85$; range $=-4$ to $39 ; M=11.6, S D$ $=7.8$ ) was the sum of 10 variables including responses to 6 dichotomous research activity variables (coded $-1=n o, 1=$ yes) - (a) collection of literature, (b) data collection, (c) data entry, (d) helped others design a study, (e) designed own study, and (f) participated in project write-up - three separate 5-point ratings ranging from 1 (poor) to 5 (excellent) of whether participants reported having taken advantage of available research opportunities; the number of undergraduate research projects that participants reported being involved with; the number of professors that they reported having worked with as undergraduates; and participants' 5-point ratings ranging from 1 (poor) to 5 (excellent) of the research opportunities available to them at their undergraduate departments.

Faculty interaction $(\alpha=.62$; range $=0$ to $6 ; M=4.5, S D=$ 1.7) was the sum of responses on whether participants reported having had a faculty mentor as an undergraduate and participants' 5-point ratings ranging from 1 (poor) to 5 (excellent) of the quality of their interactions with faculty at their undergrad- uate departments. Faculty influence $(\alpha=.59$; range $=2$ to $10 ; M$ $=7.4, S D=2.3$ ) was the sum of participants' 5-point ratings of faculty influence ranging from 1 (poor) to 5 (excellent) and confidence ranging from 1 (strongly disagree) to 5 (strongly agree) in faculty letters of recommendation. Applied experience $(\alpha=$ .61 ; range $=2$ to $10 ; M=6.3, S D=2.2)$ was the sum of 5-point ratings ranging from 1 (poor) to 5 (excellent) of availability of applied experience and whether the participant took advantage of applied experiences at the undergraduate program.

In addition, there were several independent variables that were not grouped for statistical and theoretical reasons and have not been previously described. We assessed family income on a 5 -point rating scale ranging from $1(\$ 0$ to $\$ 15,000)$ to 5 (above $\$ 100,000)$ with the greatest percentage of participants falling within the $\$ 50,001$ to $\$ 100,000$ range (40.8\%). Participants also indicated the number of conference presentations they made as undergraduates (range $=0$ to $7 ; M=0.33, S D=0.80$ ), the number of scholarly publications they accumulated as undergraduates (range $=0$ to $3 ; M=0.22, S D=0.55$ ), and their undergraduate GPAs (range $=2.20$ to $4.0 ; M=3.56, S D=0.32$ ).

We divided the predictor variables, including the aggregated variables described previously, into three conceptually discrete categories based on prior research and theoretical understanding of the variables: Level 1 individual-specific and undergraduate program variables; Level 2 faculty interaction; and Level 3 achievement, experience, and faculty influence variables. We expected Level 2 and Level 3 variables to mediate relations between Level 1 variables and the dependent variable, self-rated preparedness for graduate school. We expected Level 3 variables to mediate relations between the Level 2 variable and selfrated preparedness for graduate school. In other words, we expected that paths from lower level predictors to self-rated preparedness for graduate school would, at least in part, be indirectly routed through higher level predictors.

We explored all possible interactions among the predictor variables in relation to self-rated preparedness for graduate school; however, we do not present any interactions because relations did not emerge beyond the level expected by chance when taking into account family wise error. For the sake of parsimony, we exclude interactions from the analyses presented here.

The model accounted for a significant amount of variance in self-rated preparedness for graduate school, $R^{2}(13,643)=$ $.24, p<.001$ at Level 3. Direct effects appear in Figure 1 (thickness of regression lines in Figure 1 correspond to strength of the accompanying beta weights). Total, direct, and indirect effects on self-rated preparedness for graduate school appear in Table 1. Level 1 total effects of undergraduate program, statistics required, and Psi Chi member on self-rated preparedness for graduate school were partially mediated by Level 2 and Level 3 variables (see Table 1 and Figure 1).

The Level 2 variable faculty interaction partially mediated the effects of undergraduate program and Psi Chi member on self-rated preparedness for graduate school (see Table 1 and Figure 1). The total effects of undergraduate program and Psi Chi member were primarily indirect; that is, these variables were not related to self-rated preparedness for graduate school after Level 2 and Level 3 variables were taken into account. 


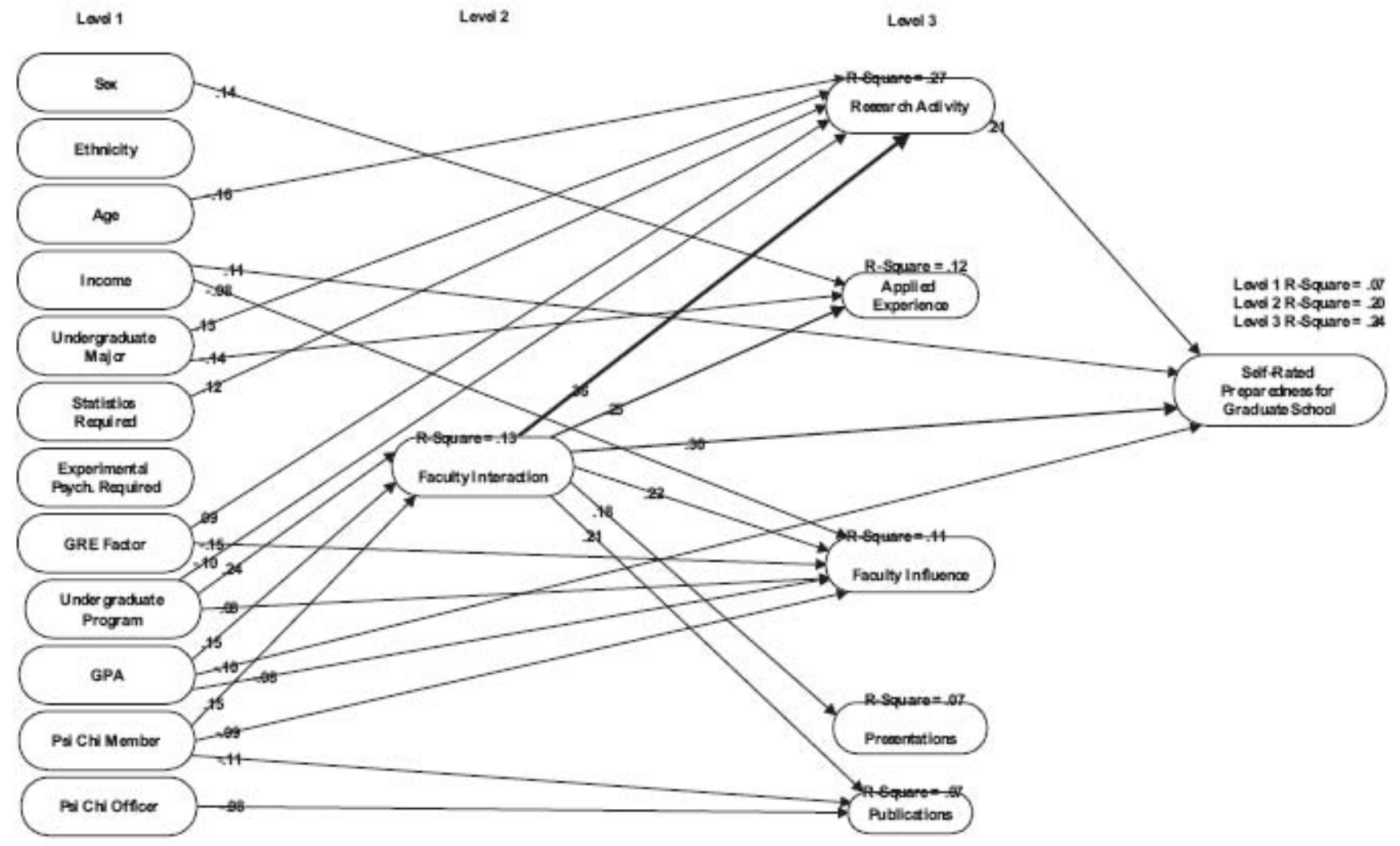

Figure 1. Path model of perceived preparation for graduate school.

Table 1. Effects of Level 1 and Level 2 Predictor Variables on Student Perceived Preparedness for Graduate School

\begin{tabular}{|c|c|c|c|}
\hline Variables & Total & Direct & Indirect \\
\hline \multicolumn{4}{|l|}{ Level 1} \\
\hline Sex & .06 & .05 & .01 \\
\hline Ethnicity & .00 & -.01 & .01 \\
\hline Age & -.07 & -.03 & -.04 \\
\hline Income & $.10^{*}$ & $.11^{* *}$ & -.01 \\
\hline Undergraduate major & .03 & .02 & .01 \\
\hline Statistics required & $.10^{*}$ & .06 & .04 \\
\hline Experimental psychology required & .07 & .08 & -.01 \\
\hline GRE Factor & .00 & .01 & -.01 \\
\hline Undergraduate program & $.13^{* *}$ & .05 & .08 \\
\hline Undergraduate GPA & -.03 & $-10^{*}$ & .07 \\
\hline Psi Chi member & $.11^{*}$ & -.04 & .15 \\
\hline Psi Chi officer & .04 & .02 & .02 \\
\hline \multicolumn{4}{|l|}{ Level 2} \\
\hline Faculty interaction & $.39 * *$ & $.30^{* *}$ & .09 \\
\hline \multicolumn{4}{|l|}{ Level 3} \\
\hline Research activity & & $.21^{*}$ & \\
\hline Faculty influence & & .04 & \\
\hline Applied experience & & .05 & \\
\hline Presentations & & .01 & \\
\hline Publications & & -.02 & \\
\hline
\end{tabular}

Note. All values represent beta weights. GRE $=$ Graduate Record Exam; GPA $=$ grade point average.

${ }^{*} p<.05 .{ }^{* *} p<.01$. 
Both undergraduate program and Psi Chi (which had significant total effects and nonsignificant direct effects on self-rated preparedness for graduate school) were predictive of faculty interaction, which in turn was related to self-rated preparedness for graduate school.

The Level 3 variable research activity also partially mediated the relation between undergraduate program and self-rated preparedness. In addition, research activity partially mediated the strong total effect of faculty interaction on self-rated preparedness, although faculty interaction still had a strong direct relation to self-rated preparedness after adding Level 3 variables in the model. Research activity also mediated the relation between statistics required and self-rated preparedness (see Figure 1 and Table 1).

\section{Discussion}

The hypothesis that a number of demographic variables and undergraduate experiences influenced students' self-rated preparedness for graduate school was supported. Two demographic variables, income and undergraduate GPA, had direct effects on self-rated preparedness. The largest single contributor to perceived preparedness was quality of interaction with an undergraduate faculty mentor. In addition, participation in research activities was a significant direct predictor of perceived preparedness. However, there were a number of additional variables that indirectly influenced perceived preparedness. We discuss these effects in more detail.

The negative relation between undergraduate GPA and perceived preparedness and the positive relation between income and perceived preparedness was curious. Students with higher GPAs might have taken easier undergraduate courses and not adequately prepared themselves for the rigorous demands of graduate school. Alternatively, higher undergraduate GPA students may have been driven to excel yet never believed that they had performed well enough. Thus, these students may have identified numerous ways in which they could have been better prepared for graduate school (i.e., shortcomings) instead of focusing on their actual abilities. The fact that students from higher incomes believed they were better prepared may be an indication of their greater exposure and comfort to higher education as well as any additional cultural advantages that could have resulted from their upbringing.

The relation between undergraduate program type and perceived preparedness was mediated by research activity and faculty interaction. Students who attended larger, public schools with graduate programs in psychology were more likely to have been involved in research as undergraduates; students from smaller private universities without graduate programs were likely to have had better faculty interaction with a mentor.

The single largest contributor to self-rated preparedness was students' interactions with faculty members at their undergraduate institution. Students who reported having a mentor and who reported high quality interactions with faculty reported feeling more prepared for graduate school. It was clear from this result that faculty can have a positive effect on their undergraduate students that extends beyond the period defined by the fac- ulty-student relationship at the undergraduate institution and influences students' perceived preparedness for graduate school.

Finally, the second largest contributor to self-rated preparation for graduate school was research activity. This finding provides support for the notion that, in addition to being important for gaining admission to graduate school, undergraduate research has continuing effects once a student is in a graduate program. It is likely that skills derived from undergraduate research experience serve as a springboard for graduate-level activities and have numerous additional effects on graduate school performance and efficacy because of the emphasis placed on research activity in graduate school.

The path model presented here suggests that there are several aspects of the undergraduate experience that influence a student's self-rated preparedness for graduate school. However, the two factors that were most influential were interactions with faculty and participation in research. These results validate the advice typically given to prospective students: Participate in research and make sure you spend time with faculty so that you get good letters of recommendation.

It was interesting that students attending a particular type of undergraduate institution were not at a clear advantage or disadvantage. Students at larger public universities with graduate programs were more likely to gain valuable research experience. Students who attended smaller, private universities without graduate programs were more likely to develop mentoring relationships, the single largest predictor of perceived preparedness. In addition, the development of this mentoring relationship was also related to research activity that then had a direct relation to perceived preparedness.

It was curious that quantifiable variables such as undergraduate GPA, GRE, publications, presentations, and even faculty letters of recommendation (as assessed in the faculty influence variable) did not demonstrate direct effects on perceived preparedness. Although these variables increase chances of success in the graduate school admission process (Couch \& Benedict, 1983; Landrum et al., 1994; Purdy et al., 1989; Smith, 1985), they did appear to distinguish those students who felt more prepared for graduate school from those who felt less prepared if one is considering only those students who were admitted to graduate school. These results may suggest a distinction between those objective variables that graduate schools use to select graduate students from vast applicant pools and those variables that indicate better preparation for graduate school. Of course, self-rated preparedness does not directly equate with success in graduate school. However, surely success in graduate school can be measured in other ways rather than by range-restricted variables such as graduate school GPA. Self-rated preparedness is simply another way to assess preparation, although it certainly is not the definitive measurement.

This study is of interest to both undergraduate and graduate faculty members who are concerned with students' graduate school preparation. There are two main points to take from this study. First, undergraduate faculty can have a profound impact on their students' sense of being well prepared for graduate school. The results of this study suggest the importance of interacting with and mentoring undergraduate students. Reducing the time spent with undergraduate students may negatively im- 
pact future graduate students' perceived preparedness for graduate school. Instructors should encourage students to seek out mentors early in their undergraduate careers and take full advantage of the informal communication and learning that often takes places in such relationships. Although the results suggest that students at larger public universities are at a disadvantage for establishing these types of relationships, their greater access to research experience appears to balance out the ultimate impact on their self-rated preparation for graduate school. Of course, individual institutions, whether smaller private schools or larger public schools, may have differences beyond the broad generalizations identified in these results.

A second point, of potential interest to graduate faculty, is that there are groups of students in graduate programs who do not believe that they are well prepared. Self-efficacy beliefs are associated with academic performance in a wide variety of academic settings. Feelings of self-efficacy are likely to influence student behavior during graduate school. In turn, student behavior during graduate school has implications for both the type of job one obtains after graduation and for one's performance of one's job. Although it is not currently known whether self-efficacy feelings regarding psychology graduate school are related to self-efficacy feelings for a career following graduate school, it seems likely that there would be some link. What is clear is that specific self-efficacy feelings are influential throughout an individual's career. For instance, research self-efficacy was significantly related to research productivity among faculty members, even after controlling for such factors as academic rank (Vasil, 1993). Given the impact feelings of efficacy can have on one's academic career, it might be beneficial to identify graduate students who do not feel well prepared and direct them toward experiences that would improve their sense of being prepared. This practice might reduce rates of students exiting graduate programs without earning a degree and also mitigate feelings of stress as well as possibly improving their later job performance. It is clear from the results of this study that objective factors such as GRE scores, which are necessary to identify those students who met the acceptance cutoffs, do not identify students who feel well prepared for graduate school and are likely to have greater self-efficacy.

Although this study included both objective measures of students' knowledge and past performance and more subjective measures of undergraduate experiences and self-rated preparedness, it is important to note that future research could build on our results by including ratings by graduate faculty, students' perceptions immediately prior to entering graduate school, and information on students who leave graduate school without obtaining a degree. In addition, empirical examinations of the mentoring relationship between students and faculty could hold a wealth of knowledge. Furthermore, there were some limitations to this sample. We included only students who were admitted, accepted an offer, and then stayed in graduate school. Finally, in this study we examined only preparation for graduate school in psychology. Students who are trained in undergraduate psychology departments enter a wide variety of careers that potentially require a variety of skills and experiences for adequate preparation. It is difficult to know how well prepared these students believe they are for other careers.

\section{References}

American Psychological Association. (1996). Graduate study in psychology (29th ed.). Washington, DC: Author.

Anderson, D. C. (1998). A focus on career: Graduate training in counseling psychology. Journal of Career Development, 25 , $101-110$.

Atkinson, D. R., Casas, A., \& Neville, H. (1994). Ethnic minority psychologists: Whom they mentor and benefits they derive from the process. Journal of Multicultural Counseling and Development, 22, 37-48.

Bandura, A. (1977). Self-efficacy: Toward a unifying theory of behavioral change. Psychological Review, 84, 191-215.

Buskist, W. (1999). Teaching an undergraduate course in preparing for graduate study in psychology. Teaching of Psychology, 26, 286-288.

Couch, J. V., \& Benedict, J. O. (1983). Graduate school admissions variables: An analysis of 1980-81 students. Teaching of Psychology, 10, 3-6.

Gilbert, L. A., \& Rossman, K. M. (1992). Gender and the mentoring process for women: Empowering women through academic and career counseling. Professional Psychology: Research and Practice, 23, 233-238.

Griffin, B. W., \& Griffin, M. M. (1997). The effects of reciprocal peer tutoring on graduate students' achievement, test anxiety, and academic self-efficacy. Journal of Experimental Education, 65, 197-209.

Habler, B. L., Vodanovich, S. J., \& Lowe, R. H. (1990). Using a weighted application blank procedure to predict success in graduate school. College Student Journal, 24, 255-260.

Hirschberg, N., \& Itkin, S. (1978). Graduate student success in psychology. American Psychologist, 33, 1083-1093.

Jacobi, M. (1991). Mentoring and undergraduate academic success: A literature review. Review of Educational Research, 61, 505-532.

Kahn, J. H., \& Scott, N. A (1997). Predictors of research productivity and science-related career goals among counseling psychology doctoral students. Counseling Psychologist, 25, 38-67.

Kierniesky, N. C. (1984). Undergraduate research in small psychology departments. Teaching of Psychology, 11, 15-18.

Landrum, R. E., Jeglum, E. B., \& Cashin, J. R. (1994). The decision-making processes of graduate admissions committees in psychology. Journal of Social Behavior and Personality, 9, 239-248.

Lent, R. W., Brown, S. D., \& Gore, P. A., Jr. (1997). Discriminant and predictive validity of academic self-concept, academic self-efficacy, and mathematics-specific self-efficacy. Journal of Counseling Psychology, 44, 307-315.

Lent, R. W., Brown, S. D., \& Larkin, K. C. (1986). Self-efficacy in the prediction of academic performance and perceived career options. Journal of Counseling Psychology, 33, 265269. 
Purdy, J. E., Reinehr, R. C., \& Swartz, J. D. (1989). Graduate admissions criteria of leading psychology departments. American Psychologist, 44, 960-961.

Smith, R. A. (1985). Advising beginning psychology majors for graduate school. Teaching of Psychology, 12, 194-198.

Szymanski, E. M., Swett, E. A., Watson, E. A., Lin, S. L., \& Chan, S. Y. (1998). The effects of contextualized research instruction on research anxiety, perceived utility of research, and confidence in research ability. Rehabilitation Education, 12, 347-360.

Vasil, L. (1993). Gender differences in the academic career in New Zealand universities. New Zealand Journal of Educational Studies, 28, 143-153.
Notes

1. Marc Patry is now at Castleton State College. Brandy Randall is now at North Dakota State University.

2. The first and third authors were supported as predoctoral fellows by an National Institutes of Mental Health Training grant, Training in Mental Health and Justice Systems Research (5T32MH16156), during the partial preparation of this article. This research would not have been completed without financial assistance from the University of Nebraska-Lincoln's RAC/Warden fund.

3. We thank Michael James and Dory Hilker for their assistance with the data entry. Thanks to Gustavo Carlo for his expertise with regard to the self-efficacy literature and helpful suggestions. Special thanks also go to the graduate departments and students who made this project possible.

4. Send correspondence and requests for the complete questionnaire to Matthew T. Huss, who is now at Department of Psychology, Creighton University, Omaha, NE 68178; e-mail: mhuss@creighton.edu 